\title{
Remoção seletiva de tecido cariado: uma revisão integrativa da literatura
}

\author{
Selective removal of carious tissue: an integrative literature review \\ Extracción selectiva del tejido cariado: revisión integrativa de la literatura
}

\author{
Isabela Cristina Silva \\ ORCID: https://orcid.org/0000-0002-9567-0618 \\ Centro Universitário de Patos de Minas, Brasil \\ E-mail: isabelacs@unipam.edu.br \\ Mariana Martins Andalécio \\ ORCID: https://orcid.org/0000-0002-7722-8199 \\ Centro Universitário de Patos de Minas, Brasil \\ E-mail: marianamartins@unipam.edu.br \\ Rodrigo Soares de Andrade \\ ORCID: https://orcid.org/0000-0001-6114-0929 \\ Centro Universitário de Patos de Minas, Brasil \\ E-mail: rodrigosa@unipam.edu.br \\ Ivania Aparecida Pimenta Santos Silva \\ ORCID: https://orcid.org/0000-0001-7012-8497 \\ Centro Universitário de Patos de Minas, Brasil \\ E-mail:ivaniapimenta@unipam.edu.br \\ Denise de Souza Matos \\ ORCID: https://orcid.org/0000-0001-6750-6215 \\ Centro Universitário de Patos de Minas,Brasil \\ E-mail: denisesm@unipam.edu.br
}

\begin{abstract}
Resumo
A doença cárie está presente com grande frequência no cotidiano clínico dos cirurgiões-dentistas, sendo sem dúvida, a mais prevalente das lesões. A remoção de tecido cariado e a substituição por materiais restauradores tem sido, há muito tempo, praticado por esses profissionais, porém o método de remoção, com o avanço do conhecimento, tem sido substituído, sobretudo por técnicas mais conservadoras. Sendo assim, o objetivo dessa revisão integrativa da literatura será reunir estudos que comprovem a indicação da remoção seletiva, comparando técnicas, materiais restauradores e taxas de sucesso. Foi realizada uma busca nas bases de dados PubMed, Scielo e Lilacs, tendo como critérios de inclusão: artigos que contemplem o assunto proposto em português e inglês, na íntegra, publicados nos últimos 10 anos, com os decritores: "cárie dentária", "remoção seletiva de tecido cariado", "tratamento". Pode-se concluir que a remoção seletiva do tecido cariado traz impactos positivos no manejo de lesões de cárie profundas e, por carecer de uma técnica simples, minimamente invasiva e com resultados pulpares promissores, tem grandes indicações dentro da filosofia da odontologia de mínima intervenção.
\end{abstract}

Palavras-chave: Cárie dentária; Dente decíduo; Dente permanente; Tratamento.

\begin{abstract}
The carious disease is present with great frequency in the daily clinical routine of dental surgeons, and is undoubtedly the most prevalent of the lesions. The removal of carious tissue and replacement by restorative materials has long been practiced by these professionals, but the removal method, with the advancement of knowledge, has been replaced, especially by more conservative techniques. Therefore, the aim of this integrative literature review is to gather studies that prove the indication of selective removal, comparing techniques, restorative materials, and success rates. A search was conducted in the PubMed, Scielo and Lilacs databases, using as inclusion criteria: articles that address the proposed subject in Portuguese and English, in full, published in the last 10 years, with descriptors: "dental caries", "selective removal of decayed tissue", "treatment". It can be concluded that the selective removal of decayed tissue brings positive impacts in the management of deep caries lesions, and because it is a simple, minimally invasive technique with promising pulpal results, it has great indications within the philosophy of minimal intervention dentistry.
\end{abstract}

Keywords: Dental cavity; Deciduous tooth; Permanent tooth; Treatment.

\section{Resumen}

La enfermedad de la caries está presente con gran frecuencia en la práctica clínica diaria de los odontólogos y es sin duda la más prevalente de las lesiones. Estos profesionales han practicado durante mucho tiempo la extracción de 
tejido descompuesto y el reemplazo con materiales de restauración, pero el método de extracción, con el avance del conocimiento, ha sido reemplazado, especialmente por técnicas más conservadoras. Por lo tanto, el objetivo de esta revisión integradora de la literatura será recopilar estudios que demuestren la indicación de remoción selectiva, comparando técnicas, materiales restauradores y tasas de éxito. Se realizó una búsqueda en las bases de datos PubMed, Scielo y Lilacs, teniendo como criterios de inclusión: artículos que cubran el tema propuesto en portugués e inglés, en su totalidad, publicados en los últimos 10 años, con los descriptores: "caries dental", "eliminación selectiva de tejido descompuesto", "tratamiento". Se puede concluir que la remoción selectiva de tejido cariado tiene impactos positivos en el manejo de las lesiones cariosas profundas y, al carecer de una técnica simple, mínimamente invasiva y con resultados pulpares prometedores, tiene grandes indicaciones dentro de la filosofía de la odontología de mínima intervención.

Palabras clave: Cavidad dental; Diente de hoja caduca; Diente permanente; Tratamiento.

\section{Introdução}

A cárie dentária é definida como uma doença que pode apresentar comportamento crônico ou agudo, não transmissível e propensão dinâmica. A prevalência da doença é alta, embora nos últimos anos tem se observado o declínio desse índice. É apontada, ainda, como um problema de saúde pública e a maior responsável pela perda de dentes em todas as idades (Abanto, Berti, Miguita\& Bonecker, 2016). A destruição gradual patológica do tecido dentário por microrganismos orais afetaindivíduos de diferentes culturas e classes socioeconômicas (Silveira, et al., 2015).

Em relação a sua etiologia é estabelecido globalmente que a cárie dental é uma doença multifatorial e o primeiro modelo proposto para explicar esse fenômeno foi o Diagrama de Keyes (1960), fundamentado na interação de fatores determinantes como dente suscetível, substrato (dieta cariogênica) e microrganismos. Todavia, para Newbrun (1983), além dos fatores propostos por Keyes, o autor julgou importante acrescentar o fator tempo para o surgimento da cárie (Keyes, 1960; Newbrun, 1983).

A doença ocorre, em definições fisiopatológicas, quando existe um desequilíbrio físico e químico entre a estrutura do dente e o biofilme (Carvalho,et al., 2018). Esse desequilíbrio no conhecido processo de desmineralização e remineralização que ocorre constantemente na cavidade bucal, deriva da perda de íons cálcio e fosfato dos tecidos duros, levando ao início da lesão de cárie e à destruição do elemento dentário (Fejerskov, Nyvad\& Kidd, 2017).

O processo da cárie inicia-se no esmalte, podendo se apresentar no estado de lesão não cavitada ou com cavidade; nessa segunda vertente, não havendo a paralisação da lesão, estruturas anexas podem ser envolvidas e uma intervenção precisará ser realizada (Valentin, Silva\& Castro, 2017).

Para definir o melhor manejo das lesões já cavitadas e com comprometimento de esmalte e dentina, é preciso entender que o conceito biológico da cárie separa a dentina cariada em externa e interna. A dentina externa, também conhecida como infectada, é a parte mais contaminada, de textura amolecida e aspecto úmido, sendo que a dentina interna, vulgo afetada, apresenta consistência mais rígida e geralmente com coloração acastanhada, é a mais profunda e passível de remineralização (Azevedoet al., 2011).

A cárie dentária é, portanto, um processo complexo, que se torna extremamente difícil de compreender, mas pode ser controlada a qualquer instante se a relação causa-efeito for transfigurada. Devido a essa complexidade, o tratamento das lesões cariosas faz parte da rotina do cirurgião-dentista e vem sendo uma questão bastante argumentada na literatura por diversos autores (Azevedo,et al., 2011; Maltz \& Jardim,2014).

Durante muito tempo a terapêutica preconizada se resumia à remoção total do tecido cariado, ou seja, de toda dentina e esmalte comprometidos pela cárie, além dos tecidos sem suporte, com o propósito de criar um meio livre de bactérias, que era considerado ideal para paralisar a açãocariogênica (Araújo,et al., 2017). Esse método invasivo e com manipulação direta do tecido pode ocasionar, especialmente nos casos de lesõesprofundas, o comprometimento da saúde do complexo pulpar e, consequentemente, umaredução drástica das taxas de sucesso clínico (Firmino-Bitello,et al., 2018). 
Com a busca incessante de novos conhecimentos e o estudo mais detalhado sobre o processo da doença cárie, vem se buscando na odontologia moderna, abordagens mais conservadoras. Dentro desse panorama, o protocolo de remoção seletiva de tecido cariado (RSTC) tem sido colocado em pauta, a fim de preservar ao máximo a estrutura dentária e manter a integridade da polpa, desde que certos princípios de diagnóstico sejam respeitados. Essa técnica consiste na limpeza completa das paredes circundantes com colher de dentina ou instrumento rotatório em baixa rotação, porém, nas paredes de fundo, somente a dentina infectada, não passível de remineralização, é cuidadosamente removida com o auxílio de instrumentos manuais (Valentin, et al., 2017). A remoção seletiva da dentina cariada deve estar associada a um bom selamento da cavidade e essa restauração deve impedir a entrada de nutrientes para as bactérias remanescentes, reduzindo o número de microrganismos e, com isso, impedindo a progressão da lesão (Jardim, Simoneti\& Maltz, 2015).

A odontologia minimamente invasiva traz inúmeras vantagens em relação à odontologia tradicional e, nesse contexto, ressalta-se que por se tratar de uma técnica simples e de fácil execução é, também, de grande alcance social, uma vez que pode dispensar o paciente de tratamentos mais onerosos (Mota, Leite \& Targino, 2013).

Tendo em vista os fatos apresentados, a cárie dentária é uma doença de alta prevalência e que exige um protocolo eficaz, de preferência conservador e minimamente invasivo, para seu controle e tratamento. Devido a esse argumento, trabalhos como este podem contribuir de maneira significativa, por relatar uma temática relativamente recente, que é a técnica de remoção seletiva de tecido cariado, avaliando o sucesso da técnica e comparando resultados entre diferentes métodos, o que irá interferir diretamente na tomada de decisão do cirurgião-dentista, bem como aumentar as possibilidades de tratamento e as taxas de sucesso clínico.

\section{Metodologia}

O presente trabalho trata-se de uma pesquisa de natureza básica estratégica, qualitativa, de caráter descritivo exploratório (Estrela, 2018).

\subsection{Estratégia de busca}

Foram selecionados estudos indexados nas bases eletrônicas de dados PubMed, Scielo e Lilacs. Foram utilizados para a pesquisa os seguintes descritores e suas combinações nas línguas portuguesa e inglesa:“cárie dentária", "remoção seletiva de tecido cariado", "tratamento", associados por meio do operador booleano "and".

\subsection{Critérios de inclusão e exclusão}

Os critérios de inclusão para a seleção dos artigos que foram utilizados na pesquisa são: (i) artigos publicados em português e inglês; (ii) artigos na íntegra que retratassem o conteúdo referente à temática da revisão integrativa; (iii) artigos publicados nas bases de dados citadas nos últimos dez anos (2011/2021).

Os critérios de exclusão foram: (i) artigos com mais de dez anos de publicação; (ii) artigos com idiomas diversos ao designado; (iii) teses; (iv) revisões; (v) artigos com textos incompletos; (vi) artigos duplicados nas bases de dados.

Com base nos critérios citados e após o descarte dos artigos que não se encaixavam no intuíto na pesquisa (Figura 1), foram encontrados 09 artigos que serão apresentados a seguir nos resultados, estes foram rotolados com base no instrumento "Oxford Centre for Evidence-based Medicine".

\section{Resultados}

Do total de 377 encontrados por meio da estratégia de busca na literatura por meio dos descritores, foram incluidos na amostra final 18 artigos. Os excluídos nessa etapa incial foram aqueles em que o título e o resumo não se enquadravano objetivo 
do trabalho, e também por motivos diversos relacionados os critérios de exclusão. Todos os outros estudos foram selecionados e, então, lidos na íntegra, sendo que 09 artigos foram usados para a discussão da pesquisa (Figura 1).

Os artigos selecionados foram organizados na tabela a seguir (Tabela 1), onde estão descritas as principais informações. Todos os trabalhos foram classificados em 1B, de acordo com o método "Oxford Centre for Evidence-based Medicine" que classifica os trabalhos de acordo com o tipo de estudo e seu nível de evidência científica.

Figura 1 - Fluxograma referente à seleção dos artigos.

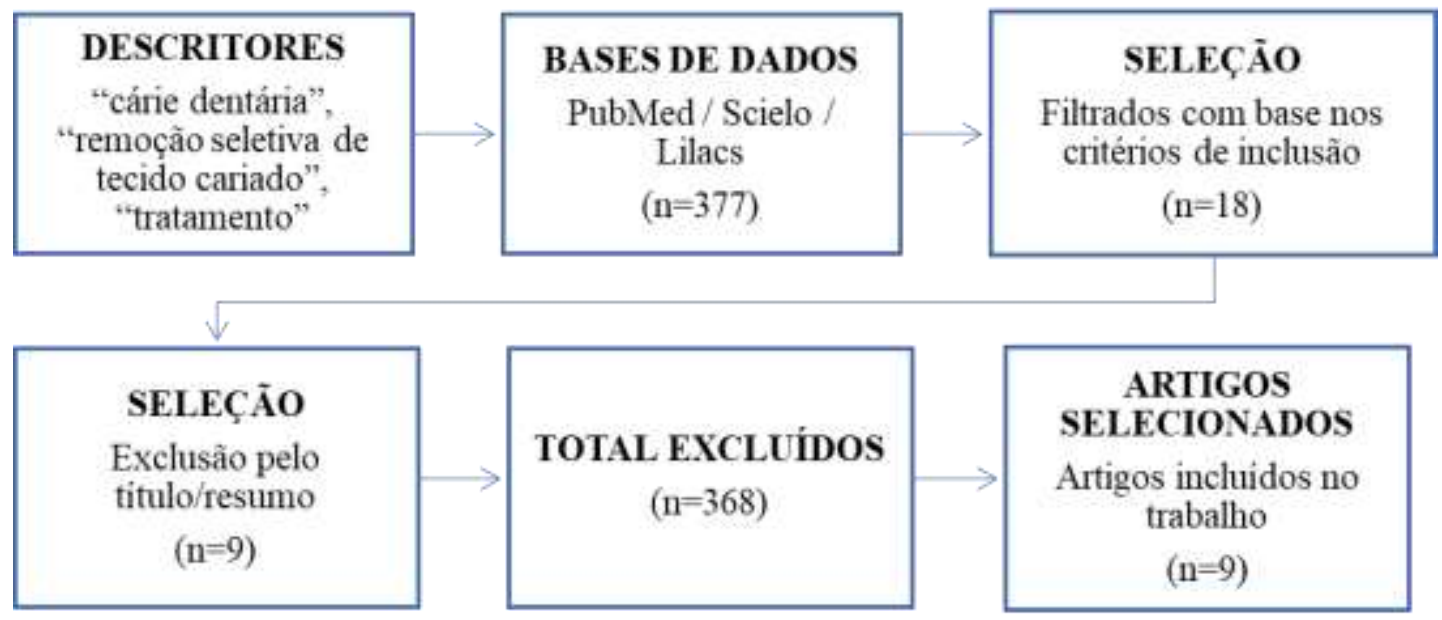

Fonte: Autores (2021).

Tabela 1: Caracterização dos estudos segundo a autoria / ano de publicação, título do artigo, periódico, objetivos, método e principais resultados.

\begin{tabular}{|c|c|c|c|c|c|}
\hline $\begin{array}{c}\text { AUTORES/ } \\
\text { ANO }\end{array}$ & TÍTULO & $\begin{array}{c}\text { PERÍODICO } \\
\text { (REVISTA) }\end{array}$ & OBJETIVO & MÉTODO & RESULTADO \\
\hline $\begin{array}{l}\text { Franzon et } \\
\text { al., 2014. }\end{array}$ & $\begin{array}{l}\text { Outcomes of one-step } \\
\text { incomplete and } \\
\text { complete excavation in } \\
\text { primary teeth: a 24- } \\
\text { month randomized } \\
\text { controlled trial. }\end{array}$ & Caries Research & $\begin{array}{l}\text { Comparar em } 24 \text { meses } \\
\text { os resultados da saúde } \\
\text { pulpar após remoção } \\
\text { parcial de cárie (RPC) } \\
\text { e remoção total de cárie } \\
\text { (RTC) em molares } \\
\text { decíduos. }\end{array}$ & $\begin{array}{c}\text { Ensaio } \\
\text { clínico } \\
\text { randomizado }\end{array}$ & $\begin{array}{l}\text { Exposição à polpaocorreu em } 27,5 \% \text { dos } \\
\text { dentes tratados com RPC e RTC. O } \\
\text { tempo operatório foi significativamente } \\
\text { maior para RTC. As taxas de sucesso } \\
\text { foram de } 92 \text { e } 96 \% \text { para os grupos RPC e } \\
\text { RCC. O sucesso tendeu a ser menor em } \\
\text { lesões oclusoproximal (92\%) do que em } \\
\text { oclusal(100\%). }\end{array}$ \\
\hline $\begin{array}{l}\text { Franzon et } \\
\text { al.,2015. }\end{array}$ & $\begin{array}{l}\text { Randomized controlled } \\
\text { clinical trial } \\
\text { Of 24-months survival } \\
\text { of composite resin } \\
\text { restorations after one- } \\
\text { step incomplete and } \\
\text { completeexcavation on } \\
\text { primary teeth. }\end{array}$ & $\begin{array}{l}\text { Journal of } \\
\text { Dentistry }\end{array}$ & $\begin{array}{l}\text { Comparar no período } \\
\text { de } 24 \text { meses a } \\
\text { sobrevida de } \\
\text { restaurações em resina } \\
\text { composta em molares } \\
\text { decíduos após RPC e } \\
\text { RTC. }\end{array}$ & $\begin{array}{l}\text { Ensaio } \\
\text { clínico } \\
\text { randomizado }\end{array}$ & $\begin{array}{l}\text { Restaurações emmolares decíduos } \\
\text { mostraram sobrevida aceitável de } 76 \% \text {. } \\
\text { Remoção parcial resultou em menos } \\
\text { exposições de celulose, mas mais falhas } \\
\text { de restauração. Remoção totalaumentou } \\
\text { o sucesso restauradorem } 86 \% \text {, } \\
\text { masresultou significadamente em mais } \\
\text { exposições de celulose. }\end{array}$ \\
\hline $\begin{array}{l}\text { Jardim, } \\
\text { Simoneti\& } \\
\text { Maltz, } 2015 .\end{array}$ & $\begin{array}{c}\text { Remoção parcial de } \\
\text { tecido cariado } \\
\text { em dentes } \\
\text { permanentes: seis anos } \\
\text { de } \\
\text { acompanhaento. }\end{array}$ & $\begin{array}{l}\text { RFO, Passo } \\
\text { Fundo }\end{array}$ & $\begin{array}{l}\text { Comparar aefetividade } \\
\text { do tratamento } \\
\text { alternativo deremoção } \\
\text { parcial de tecido } \\
\text { cariado (RPTC) em } \\
\text { uma única sessão ao } \\
\text { tratamento expectante } \\
\text { (TE), após seis anos de } \\
\text { acompanhamento. }\end{array}$ & $\begin{array}{l}\text { Ensaio } \\
\text { clínico } \\
\text { randomizado }\end{array}$ & $\begin{array}{l}\text { Foram observadas taxas de sucesso de } \\
60 \% \text { para o grupo RPTC e } 32 \% \text { para o } \\
\text { grupo TE. }\end{array}$ \\
\hline
\end{tabular}




$\begin{array}{ccc}\text { Léda et } & \text { Dentin optical density } \\ \text { al.,2015. } & \text { in molars subjected to } & \text { The journal of } \\ \text { partial carious } & \begin{array}{c}\text { Avaliar as mudanças na } \\ \text { densidade óptica da }\end{array} \\ \text { dentin removal. } & \begin{array}{c}\text { pediatric } \\ \text { dentistry }\end{array} & \begin{array}{c}\text { dentina em molares } \\ \text { decíduos com cárie } \\ \text { profunda, três a seis }\end{array} \\ & & \text { meses após terem sido } \\ & & \text { submetidos à remoção } \\ & \text { parcial de dentina } \\ & \text { cariada. }\end{array}$

\begin{tabular}{|c|c|c|c|c|}
\hline $\begin{array}{l}\text { Elhennawy } \\
\text { et al., } 2018 .\end{array}$ & $\begin{array}{l}\text { Selective vs stepwise } \\
\text { removal of deep } \\
\text { carious lesions in } \\
\text { primary molars: } 12- \\
\text { Months results of a } \\
\text { randomized controlled } \\
\text { pilot trial. }\end{array}$ & $\begin{array}{l}\text { Journal of } \\
\text { Dentistry }\end{array}$ & $\begin{array}{c}\text { Comparar o sucesso, a } \\
\text { sobrevivência, os } \\
\text { custos do tratamento } \\
\text { inicial, acompanhando } \\
\text { e avaliando pacientes, } \\
\text { dentistas e pais de RS e } \\
\text { ET. }\end{array}$ & $\begin{array}{l}\text { Ensaio piloto } \\
\text { randomizado }\end{array}$ \\
\hline $\begin{array}{c}\text { Firmino- } \\
\text { Bitello et al., } \\
2018 .\end{array}$ & $\begin{array}{l}\text { Microbial load after } \\
\text { aelective and } \\
\text { complete caries } \\
\text { removal in permanent } \\
\text { molars: arRandomized } \\
\text { clinical trial. }\end{array}$ & $\begin{array}{c}\text { Brazilian Dental } \\
\text { Journal }\end{array}$ & $\begin{array}{c}\text { Comparar os } \\
\text { microorganismo } \\
\text { remanescenntes } \\
\text { (anaeróbio total, } \\
\text { espécies de } \\
\text { Streptococcus e } \\
\text { espécies de } \\
\text { Lactobacillus) após a } \\
\text { remoção completa e } \\
\text { seletiva de cárie e } \\
\text { selamento da cavidade. }\end{array}$ & $\begin{array}{c}\text { Ensaio } \\
\text { clínico } \\
\text { randomizado }\end{array}$ \\
\hline
\end{tabular}

$\begin{array}{cc}\text { Ensaio } & \text { Durante o intervalo entre o tempo zero e } \\ \text { clínico cego } & \text { três meses, os níveis de tons de cinza da } \\ \text { e controlado } & \text { dentina afetada variaram de } 80,99 \pm 3,17 \\ & \text { a } 98,57 \pm 3,17 . \text { Os valores para dentina } \\ & \text { saudável, variaram, tendo um aumento } \\ \text { médio de quatro nos níveis de tons de } \\ \text { cinza. Tanto a dentina saudável quanto a } \\ \text { afetada apresentaram comportamento } \\ \text { semelhante. }\end{array}$

Durante a terapia inicial, a exposição pulpar ocorreu em 2 molares em SW (na segunda etapa) e em nenhum dente em

SE. Avaliação de pacientes, pais e dentistas não diferiu significativamente entre os grupos. Sendo que os custos de tratamento inicial e total foram maiores em ET do que RS.

RCC resultou em menores contagens de microorganismos viáveis $(\mathrm{p} \leq 0,001)$,

Streptococcus spp. $(\mathrm{p} \leq 0,001) \mathrm{e}$

Lactobacillus spp. $(\mathrm{p} \leq 0,001)$.

Entretanto, após o selamento, ocorreuuma redução significativa nas contagens totais de microrganismos viáveis,Streptococcus spp. e Lactobacillus spp. Resultou em nenhuma diferençaentre os grupos após 3 meses.

\begin{tabular}{|c|c|c|c|c|c|}
\hline $\begin{array}{l}\text { Labib et al., } \\
2019 .\end{array}$ & $\begin{array}{l}\text { Selective versus } \\
\text { stepwise removal of } \\
\text { deep carious lesions in } \\
\text { permanent teeth: } \\
\text { a randomised } \\
\text { controlled trial from } \\
\text { Egypt- an interim } \\
\text { analysis. }\end{array}$ & BMJ Open & $\begin{array}{l}\text { Comparar o sucesso, } \\
\text { sobrevivência e custos } \\
\text { da remoção seletiva de } \\
\text { tecido cariado versus } \\
\text { gradual (RS/ET)em } \\
\text { dentes permanentes } \\
\text { com cárie profunda. }\end{array}$ & $\begin{array}{c}\text { Ensaio } \\
\text { clínico } \\
\text { randomizado } \\
\text { controlado, } \\
\text { unicentro, } \\
\text { agrupado } \\
\text { dois braço }\end{array}$ & $\begin{array}{l}\text { Os dentistas podem escolher RS ou ET } \\
\text { paraotratamento de lesões cariosas } \\
\text { profundas, embora com base no } \\
\text { estudo,não há justificativa forte para } \\
\text { preferir ET em vez de RS. }\end{array}$ \\
\hline $\begin{array}{l}\text { Elhennawy } \\
\text { et al., 2020. }\end{array}$ & $\begin{array}{l}\text { Selective vsstepwise } \\
\text { removal of deep } \\
\text { carious lesions in } \\
\text { primary } \\
\text { molars: } 24 \text { months } \\
\text { follow-up from a } \\
\text { randomized controlled } \\
\text { trial. }\end{array}$ & $\begin{array}{l}\text { Clinical Oral } \\
\text { Investigations }\end{array}$ & $\begin{array}{c}\text { Comparar durante } 24 \\
\text { meses, o sucesso, a } \\
\text { sobrevida, os custos e a } \\
\text { qualidade das } \\
\text { restaurações colocadas } \\
\text { apósRSversus ET em } \\
\text { lesões de cárie } \\
\text { profunda emmolares } \\
\text { decíduos. }\end{array}$ & $\begin{array}{c}\text { Ensaio } \\
\text { clínico } \\
\text { randomizado }\end{array}$ & $\begin{array}{l}\text { A remoção seletiva de cárie é tão } \\
\text { satisfatória quanto a remoção completa } \\
\text { de cárie na redução da infecção } \\
\text { dentinária após três meses com } \\
\text { selamento da lesão. }\end{array}$ \\
\hline $\begin{array}{c}\text { Jardim et al., } \\
2020 .\end{array}$ & $\begin{array}{l}\text { Restorations after } \\
\text { selective caries } \\
\text { removal: } 5 \text {-year } \\
\text { randomized trial. }\end{array}$ & $\begin{array}{l}\text { Journal of } \\
\text { Dentistry }\end{array}$ & $\begin{array}{c}\text { Comparar a } \\
\text { sobrevivência de } \\
\text { restaurações colocadas } \\
\text { em lesões cariosas } \\
\text { profundasapós a } \\
\text { remoção seletiva de } \\
\text { cárie, ao longo de um } \\
\text { período de } 5 \text { anos. E } \\
\text { investigar se o material } \\
\text { (amálgama ou } \\
\text { resinacomposta) afeta } \\
\text { essa sobrevivência. }\end{array}$ & $\begin{array}{l}\text { Ensaio } \\
\text { clínico } \\
\text { randomizado } \\
\text { multicêntrico } \\
\text { controlado }\end{array}$ & $\begin{array}{c}\text { A análise de sobrevida de } 5 \\
\text { anosmostraram taxas de sucesso } \\
\text { semelhantes para SW }(76 \%) \text { e RPTC } \\
(79 \%) \text {, semdiferença entre os grupos. } \\
\text { Em relação ao material de } \\
\text { preenchimento, amálgama e resina } \\
\text { composta mostraram taxas de } \\
\text { sobrevivência semelhantes durante esse } \\
\text { périodo de tempo. }\end{array}$ \\
\hline
\end{tabular}

Legenda: RPC: remoçãoparcial de cárie / RTC: remoção total de cárie / RPTC:remoção parcial de tecido cariado / TE: tratamento expectante / RS: remoção seletiva / ET: escavação em etapas / RCC: remoção completa de cárie. Fonte: Autores (2021).

\section{Discussão}

A partir do diagnóstico minucioso da lesão de cárie, principalmente a verificação de sua extensão, um leque de possibilidades de tratamentos pode ser arquitetado, desde medidas de controle do biofilme até o bloqueio mecânico por meio da 
terapia restauradora.

O tratamento de lesões de cárie profundas tem se tornado um grande desafio e, sendo assim, novos protocolos clínicos têm sido colocados em pauta para a remoção do tecido. Três formas de terapia têm ganhado bastante discussão, sendo elas a remoção total, a escavação em duas etapas e a remoção seletiva de tecido cariado em uma única sessão (Franzon,et al., 2014; Franzon, et al.,2015; Jardim, et al., 2015; Léda, et al.,2015; Elhennawy, et al., 2018; Firmino-Bitello, et al., 2018; Elhennawy, et al., 2020 \& Jardim, et al., 2020).

Firmino-Bitello,et al., (2018) desenvolveram um estudo randomizado comparando a carga microbiana após a remoção seletiva de tecido cariado (RSC) e remoção completa (RCC) em molares permanentes de 34 pacientes, demonstrando que a remoção parcial é tão satisfatória e indicável quanto à completa, pois não houve uma discrepância expressiva entre a contagem de bactérias viáveis antes e após selamento da cavidade. Os pacientes do grupo RSC tiveram a remoção integral da cárie nas paredes circundantes e a retirada parcial e seletiva na parede pulpar, sendo que o grupo RCC teve a remoção total do tecido cariado de acordo com os critérios de dureza. Ambos foram selados com ionômero de vidro e reabertos após três meses para avaliação. Diante do exposto nesse estudo, os autores concluíram que a remoção total não deixa a cavidade isenta de microrganismo e pode levar a danos pulpares desnecessários, não justificando a recomendação desta técnica.

Franzon,et al. (2014), durante 24 meses, compararam por meio de um ensaio clínico, assim como no estudo citado acima, os resultados inerentes à remoção parcial e à remoção total do tecido afetado pela doença cárie, tendo como público participante crianças com pelo menos um molar decíduo cariado. O controle do resultado foi realizado por meio de exames clínicos e radiográficos, utilizando como critério de falha os sintomas agudos pulpares. Perante esse trabalho, ambas as técnicas obtiveram alta taxa de sucesso, contudo enfatizaram, sobretudo, a exigência de um menor tempo de cadeira para a remoção seletiva. Foi analisado também nesse estudo, se a relação de faces envolvidas, ou seja, o tipo de cavidade tem associação com o desfecho final do procedimento e os autoresconcluíram que as lesões oclusais com envolvimento das faces proximais apresentaram taxas de sucesso inferiores.

Jardim, et al., (2015) acompanharam, em um período de seis anos, a efetividade entre a remoção parcial de tecido cariado (RPTC) em uma única sessão e o tratamento expectante (TE). A amostra contava com pacientes com lesão de cárie profunda em molares permanentes com resposta positiva ao teste térmico de vitalidade pulpar. No tratamento expectante a remoção da dentina atingida foi realizada em duas consultas como protocolo, sendo que na primeira se realizou a remoção superficial da dentina infectada, seguido do forramento com material para proteção pulpar e, em seguida, a restauração provisória foi realizada. Em uma segunda etapa, todo o tecido cariado remanescente foi removido e a restauração definitiva produzida. Neste estudo 64 dentes foram submetidos à remoção parcial, alcançando 46 sucessos e 18 insucessos, ao passo que dos 63 dentes com remoção total, 34 deles apresentaram sucesso e 29 insucessos. Além desses resultados, observou-se, ainda, uma taxa elevada da manutenção da vitalidade pulpar quando aplicado a RPTC, o que enfatiza uma melhor preservação do elemento dentário se comparado ao tratamento expectante, possibilitando uma reabilitação mais simples, rápida e acessível aos pacientes.

Labib,et al. (2019), por meio de um estudo unicêntrico de dois braços, realizado no Egito, compararam o desfecho clínico após a remoção seletiva (RS) e a escavação em etapas (ET) em dentes permanentes. Foram alocados para essa análise, elementos dentários com lesões cariosas envolvendo mais de dois terços da dentina e que apresentavam polpas vitais. Como rege as diretrizes internacionais, na primeira intervenção, a remoção do tecido comprometido pela cárie foi executada em ambos os grupos, juntamente com uma restauração provisória em ionômero de vidro. Já na segunda visita, o material provisório foi rebaixado nos pacientes do grupo RS, de modo que o material exercitasse sua função forradora, ao passo que nos pacientes do grupo ET, todo material foi removido para prosseguir com a segunda fase. Após isso, todos os dentes foram restaurados com resina composta de forma definitiva, respeitando todos os passos obrigatórios para o sucesso da técnica e acompanhados por um 
ano. De acordo com a avaliação desse estudo, os autores compreenderam que o grupo RS apresentou uma taxa de sucesso 4,5\% maior se comparado ao grupo ET. Em relação ao custeio das técnicas, obtiveram preços semelhantes, pois ambas foram realizadas em duas etapas, com o intuito de impedir viés na pesquisa. Foi possível concluir que a remoção parcial por meio do tratamento pulpar indireto deve ser encorajada, por apresentar resultados satisfatórios.

Léda,et al. (2015), desenvolveram um estudo clínico cego e controlado, com o objetivo de avaliarem a densidade óptica da dentina em molares decíduos com cárie profunda, após a remoção seletiva de tecido cariado. Em um período de 3 a 6 meses, foram analisados 32 elementos dentários de pacientes com idade escolar. Após a remoção seletivado tecido cariado, por meio da técnica de máxima preservação, foram executadas as restaurações com ionômero de vidro e o acompanhamento por meio de radiografias bite wing. Os resultados do estudo apoiaram de maneira significativa esse protocolo, pois observaram a reorganização da matriz colágena e o aumento da opacidade da dentina, principalmente nos primeiros meses, caracterizando a remineralização, forte evidência de que a camada de dentina deixada no fundo da cavidade não causa risco à saúde bucal.

Elhennawy,et al. (2018), ao realizarem um ensaio piloto em pacientes com cárie profunda em molares decíduos sem qualquer sintomatologia dolorosa e com polpa vital, em um intervalo de tempo de 12 meses, com o intuito de verificar o desfecho clínico, o gasto e principalmente a sobrevida entre a remoção seletiva (RS) e remoção gradual (SW) em duas sessões, compreenderam que ambos os tratamentos apresentaram sucesso em lesões profundas. Porém, quando comparados, o SW possui um custo mais elevado, por depender de consultas adicionais e apresenta maior risco de carecer de pulpotomia especialmente na segunda etapa da escavação, ao passo que a SE diminui os riscos de exposição pulpar, possibilitando uma redução nas taxas de insucesso pós-operatório.

Elhennawy,et al. (2020) na mesma linha de raciocínio do estudo anterior, realizaram um ensaio clínico com acompanhamento de 24 meses entre a remoção seletiva (SE) e remoção gradual (ET) em primeiros molares com lesão profunda e, além dos resultados já alcançados na primeira pesquisa, observaram o desempenho das restaurações feitas após a retirada do tecido cariado usando as duas estratégias. Os autores puderam perceber que as restaurações em RS tiveram danos relacionados à sua integridade mais rapidamente, especialmente a descolação de suas margens, se comparado ao ET. Esse evento no trabalho foi atribuído à quantidade de tecido afetado deixado no interior da cavidade, podendo assim, interferir na longevidade da restauração devido à redução da adesão do material.

Também avaliando a durabilidade das restaurações em resina composta após as técnicas de completa e incompleta escavação de cárie, Franzon,et al., (2015), realizaram um estudo onde os examinadores foram calibrados de modo que no grupo de remoção completa todo o tecido afetado pela cárie teria que ser removido, ou passo que, na remoção parcial, a remoção seria realizada somente até alcançar a dentina com aspecto de couro. Depois da devida remoção, a cavidade foi forrada com cimento de hidróxido de cálcio e então a restauração em resina composta foi executada. Durante 24 meses foi avaliada a funcionalidade das restaurações, tendo como desfecho o sucesso em $76 \%$ delas. Comparando as duas técnicas, os autores puderem compreender que a remoção total contabiliza um número maior de exposições pulpares, porém uma maior longevidade da resina.

Jardim,et al. (2020), desenvolveram um estudo para acompanhar as restaurações após a remoção seletiva de cárie durante cinco anos. Os autores enfatizaram que a técnica minimante invasiva já está sendo empregada com resultados bastante promissores, porém o material forrador de melhor escolha ainda é investigado e, partindo desse pressuposto, avaliaram a efetividade de três materiais, sendo o hidróxido de cálcio $(\mathrm{CH})$, o agregado de trióxido mineral (MTA) e o cimento Portland (PC), cada um com suas devidas propriedades e indicações. Todos apresentaram resultados eficazes semelhantes. Portanto, de acordo com esse estudo, o sucesso da técnica não está correlacionado com o material forrador e sim com a vedação satisfatória da cavidade.

Como exposto acima, a remoção seletiva de tecido cariado, visando à interrupção do circuito metabólico dos microorganismos, bem como, a manutenção da integridade da polpa, tem sido considerada como terapia de escolha para lesões 
profundas, por apresentarem excelentes resultados como os descritos nessa revisão de literatura. Porém são necessários mais estudos seguindo essa linha de pesquisa, já que a cárie dentária é uma doença de alta prevalência e muitos profissionais niglegenciam essa forma conservadora de tratamento.

\section{Conclusão}

Embora houvesse no início uma série de indagações sobre a viabilidade da técnica de remoção seletiva em lesões profundas de cárie e ainda hoje exista uma vertente oponente a esse procedimento, essa conduta está embasada em evidências biológicas sólidas, com base científica, podendo, portanto, ser indicada e preferível devido às suas características conservadoras e eficazes em ambas as dentições.

\section{Referências}

Abanto, J., Berti, G. O., Miguita, L. \& Bonecker, M. (2016). Monitoring of caries disease by risk assessments and activity.Revista Gaúcha de Odontologia, 64(1), 70-78.

Araújo, F. A., Valois, E. M., Lago, A. D. N., Silva, B. M. A. H., Costa, J. F. \& Firoozmand, L. M. (2017). Remoção parcial do tecido cariado em dentes permanentes: uma revisão integrativa da literatura. Revista Bras. Odontol, 14(1), 31-35.

Azevedo, I. M. C., Cabral, D. F., Costa, R. C. N., Alves, C. M. C. \& Ribeiro, C. C.C. (2011). Remoção parcial de tecido cariado. Ciência e Sáude, 13(2), 88-91.

Carvalho, T. P., Signori, C., Brauner, K. V., Oliveira, E. F. \& Cenci, M. S. (2018). Desenvolvimento de lesões de cárie em dentina em um modelo de biofilme simplificado in vitro: um estudo piloto. Revista de Odontologia da UNESP, 47(1), 40-44.

Elhennawy, K. Finke, C., Paris, S., Reda, S., Jost-Brinkmann, P.G. \&Schwendicke, F. (2018). Selective vs stepwise removal of deep carious lesions in primary molars: 12 months results of a randomized controlled pilot trial. Journal of Dentistry, (77), 72-77.

Elhennawy, K., Finke, C. Paris, S.,Reda, S., Jost-Brinkmann, P.G. \&Schwendicke, F. (2020). Selective vs stepwise removal of deep carious lesions in primary molars: 24 months follow-up from a randomized controlled trial. Clin Oral Invest., 25(2), 645-652.

Estrela, C. (2018). Metodologia Científica: Ciência, Ensino, Pesquisa. Editora Artes Médicas.

Fejerskov, O., Nyvad,B. \&Kidd, E.(2017). Cárie dentária: fisiopatologia e tratamento. Guanabara Koogan.

Firmino-Bitello, L., Soares, V. K., Teixeira- Damé, N., Parolo, C. C. F. \& Maltz, M. (2018). Microbial load after selective and complete caries removal in permanent molars: a randomized clinical trial. Brazilian Dental Journal, 29(3), 290-295.

Franzon, R., Guimarães, L. F., Magalhães, C. E., Haas, A. N, \& Araujo, F. B. (2014). Outcomes of one-step incomplete and complete excavation in primary teeth: a 24-month randomized controlled trial. Caries Research. (48), 376-383.

Franzon, R., Opdam, N. J., Guimarães, L. F., Demarco, F. F., Casagrande, L., Haas, A. N. \& Araujo, F. B. (2015). Randomized controlled clinical trial of $24-$ months survival of composite resin restorations after one-step incomplete and complete excavation on primary teeth.Journal of Dentistry, 5712(15), 3001830036.

Jardim, J. J., Simoneti, M. N. D. \&Maltz, M. (2015). Remoção parcial de tecido cariado em dentes permanentes: seis anos de acompanhamento. Revista da Faculdade de Odontologia - UPF, 20(1), 39-45.

Jardim, J. J., Mestrinho, H. D., Koppe, B., Marly, L. P., Alves, L. S., Yamaguti, P. M., Almeida, J. C. F. \& Maltza, M. (2020). Restorations after selective caries removal: 5- years randomized trial. Journal of Dentistry, 5712(20), 30162-30167.

Keyes, P. H. (1960). The infectious and transmissible nature of experimental dental caries.Arch. Oral Biol., (1), 304-320.

Labib, M., Hassanein, O. E., Moussa, M., Yassen, A. \&Schwendick, F. (2019). Selective versus stepwise removal of deep carious lesions in permanent teeth: a randomised controlled trial from Egypt—an interim analysis. BMJ Open

Léda, L., Azevedo, T. D., Pimentel, P. A., De Toledo, O. A. \& Bezerra, A. C. (2015). Dentin optical density in molars subjected to partial carious dentin removal. The JournalofClinicalPediatricDentistry, 39(5), 452-457.

Maltz, M. \& Jardim, J.J. Como as pesquisas de excelência em remoção parcial de tecido cariado podem contribuir para a prática clínica? (2014). Rev. Assoc Paul CirDental., 68(4), 326-327.

Mota, L.Q., Leite, J.M.S. \& Targino, A.G.R. (2013). Dentística minimanente invasiva através da remoção parcial de dentina cariada em cavidades profundas, UNOPAR Cient. Ciênc. Biol. Saúde, 15(2), 145-152.

Newbrun, E. (1983). Cariology. Baltimore: Williams \& Wilkins.

Silveira, M. F, Freire, R. S., Nepomuceno, M. O., Martins, A. M. E. B. L, Marcopito, L. F. (2015). Cárie dentária e fatores associados entre adolescentes no norte do estado de Minas Gerais,Brasil: uma análise hierarquizada. Ciência e Saúde Coletiva, 20(11), 3351-3364.

Valentin, V. C. B., Silva, D. N. \& Castro, M.C.C. (2017). Tratamento de lesões de cárie profunda com risco de exposição pulpar: decisão baseada em evidências. Rev. Odontol.Univ.Cid., São Paulo, 29(2), 163-173. 